\title{
Marine Elements Associated with Siting of Coastal Nuclear Power Plants
}

\author{
HUANG Fa-ming ${ }^{\mathrm{a}}$, LIN Yan-hong ${ }^{\mathrm{b}}$ and WANG Chu-sheng ${ }^{\mathrm{c}}$ \\ Third Institute of Oceanography, State Oceanic Administration, Xiamen 361005, Fujian \\ Province,China \\ ahuangfaming@tio.org.cn, 'linyanhong@tio.org.cn, wangchusheng@tio.org.cn
}

Keywords: Coastal nuclear power; Siting; Marine elements.

Abstract. At present, China's nuclear power projects are mainly concentrated on the coast. The nationwide built nuclear power projects are mainly located in the three coastal provinces including Guangdong, Zhejiang and Jiangsu. The nuclear power projects under construction are also centered in the coastal 7 provinces including Guangdong, Guangxi, Hainan, Zhejiang, Liaoning, Fujian and Shandong. The serious nuclear leak at Japan Fukushima Nuclear Power Plant poses a severe problem for the world to re-examine the development of coastal nuclear power. In the present work, the characteristics of the construction of nuclear power plants in China were summarized, the major marine environment for construction of nuclear power plants and potential ecological risks were analyzed, and the marine elements associated with the siting of coastal nuclear power plants were proposed, in order to provide a reference for future siting of coastal nuclear power plants.

\section{Introduction}

Over time, China has used coal as its main energy, and North to South Coal Diversion has become the main energy transport structure. With the rapid economic development of China's eastern coastal areas, energy demand contradictions is increasingly intensifying. Development of nuclear power is an important component of long-term planning for China's power industry as well as an effective way to adjust energy structure and promote energy conservation. [1 2]

Since the grid-connected power generation of Qinshan Nuclear Power Project Phase I, China's first nuclear power plant, in 1991, a total of 11 plants with 9.068 million kilowatts at six nuclear power plants have been put into commercial operation in China. Overall, China's nuclear power plants are perfectly safe and performed well, and the operational level has been continuously improved.

However, there also exist great human and ecological safety risks in nuclear power. The issue of whether nuclear power threatens human and ecological safety has been the focus of the world's concern. The historical Three Mile Island and Chernobyl nuclear leak accidents have caused serious harm. In March 2011, serious nuclear leak was caused by earthquake and tsunami at Japan Fukushima Nuclear Power Plan [3]. Because of attaching great importance to nuclear safety, Chinese government carried out comprehensive review and safety assessment upon the built nuclear power projects and the nuclear power projects under construction, also adjusted accordingly medium- and long-term nuclear power development planning, and made it clear that inland nuclear power projects would not be arranged during the twelfth five-year plan, but nuclear power projects would be newly built in accordance with the maximum global safety requirements, which must meet three generations of nuclear technology safety standards.

The eastern coastal developed regions are the main battlefields of China's development of nuclear power. In the train of the completion and operation of Qinshan Nuclear Power Plant in 1991 and Daya Bay Nuclear Power Plant in 1994, China has built Qinshan Phase II Nuclear Power Plant, Ling Ao Nuclear Power Plant, Qinshan Phase III Nuclear Power Plant and Tian Bay Nuclear Power Plant, thus forming the three nuclear power bases including Zhejiang Qinshan, Guangdong Daya Bay and Jiangsu Tian Bay. Layout of China's nuclear power development will focus on the coastal developed regions with economically rapidly growing energy demand. Based on the siting of nuclear power plants in China and the trend of coast-based nuclear power industry cluster development, the agglomerations of nuclear power plants and nuclear power industry will appear in China's coastal 
regions[3]. Due to the presence of nonnegligible nuclear safety and ecological safety risks in nuclear power, we must strengthen research on the marine elements associated with the siting of nuclear power plants while actively promoting the development of nuclear power technology, in order to avoid relevant risks.

\section{China's Nuclear Power Development Characteristics and Spatial Distribution}

The State Council has so far approved 34 nuclear power plants, with the installed capacity of 36.92 million kilowatts. Among them, 25 plants have been started and under construction, with the installed capacity of 27.73 million kilowatts(Fig. 1). Thus, China has become the world's largest nuclear power plant construction country [1] (see Fig. 1). The nuclear power plants that are under construction and have been built are all concentrated in the coast, thus forming the 'coastal layout'. The 11 sets of built nuclear power plants are concentrated in Guangdong, Zhejiang, Jiangsu and other coastal developed provinces. Overall, China's nuclear power development and spatial layout show three characteristics: The nuclear power plants have been gradually sited from inner bays to outer bays.

The nuclear power plants that have been built in China are mainly concentrated inside the bays, such as Guangdong Daya Bay, Zhejiang Qinshan Bay and Jiangsu Tian Bay Nuclear Power Plants. In the bays, there are generally aquatic fisheries, transportation ports and other areas with relatively great sea use intensity. Meanwhile, due to slow water diffusion in the bays, the scope and extent of the impact of thermal discharge are relatively great. Some of the nuclear power plants started after 2005 have been gradually sited from outer bays to inner bays, such as Fujian Ningde Nuclear Power Plant, etc..

The development policy has shifted from moderate development to positive development and onwards to safety first.

According to the statistics of China Nuclear Energy Association, China has approved only 9.08 million kilowatts of nuclear power projects within nearly 20 years before 2005 . Since 2005 , China has approved a total of 13 nuclear power projects, including 34 plants with a total installed capacity of 37.02 million kilowatts. Besides, nearly 40 million kilowatts of nuclear power projects are still queued for approval. China's nuclear power construction is moving forward in an unprecedented prevailing trend. China's nuclear power development policy has gradually shifted from moderate development to positive development.

After the nuclear accident at Fukushima in March 2011, the executive meeting of the State Council required that the importance and urgency of nuclear safety should have been fully understood, and nuclear power development should have put safety first. It was decided that: a. Immediately conducting a comprehensive safety inspection of China's nuclear facilities. b. Effectively strengthening the safety management of running nuclear facilities. c. Conducting a comprehensive review of nuclear power plants under construction. d. Strictly approving new nuclear power projects. Close attention should be paid to the preparation of nuclear safety planning, in order to adjust and improve medium- and long-term nuclear power development plan. Before the approval of nuclear safety plan, the approval of nuclear power projects, including the preparatory projects, should be suspended. Thus, the nuclear power development policy has shifted to safety first.

The technology has safely shifted from first-generation technology to second-generation technology and onwards to third-generation technology.

As of March 2011, China had 6 operational nuclear power plants, 12 nuclear power plants under construction and 25 nuclear power plants under preparation. And the nuclear power plants within China Southern Power Grid designed 5 kinds of models, including M310 (Daya Bay), M310+ (Ling Ao Phase I), CPR100 (Ling Ao Phase II / III, Guangxi Fangchenggang, Yangjiang, Guangdong Lufeng), ERP (Taishan) and AP1000 (Guangdong Jieyang). Among them, the first three belong to a second-generation technology, and the latter two belong to a third-generation technology. Daya Bay and Ling Ao A plant use a second-generation technology, Ling Ao B plant uses a second-generation plus technology. Shandong Haiyang and Zhejiang Shanmen nuclear power plants use AP1000 third-generation technology.

On October 24, 2012, the executive meeting of the State Council adopted Nuclear Safety Planning (2011-2020) and Medium- and Long-term Nuclear Power Development Plan (2011-2020), clearly 
requiring that nuclear power projects should be newly built in accordance with the world's maximum safety requirements and the nuclear power plants must meet three generations of safety standards.

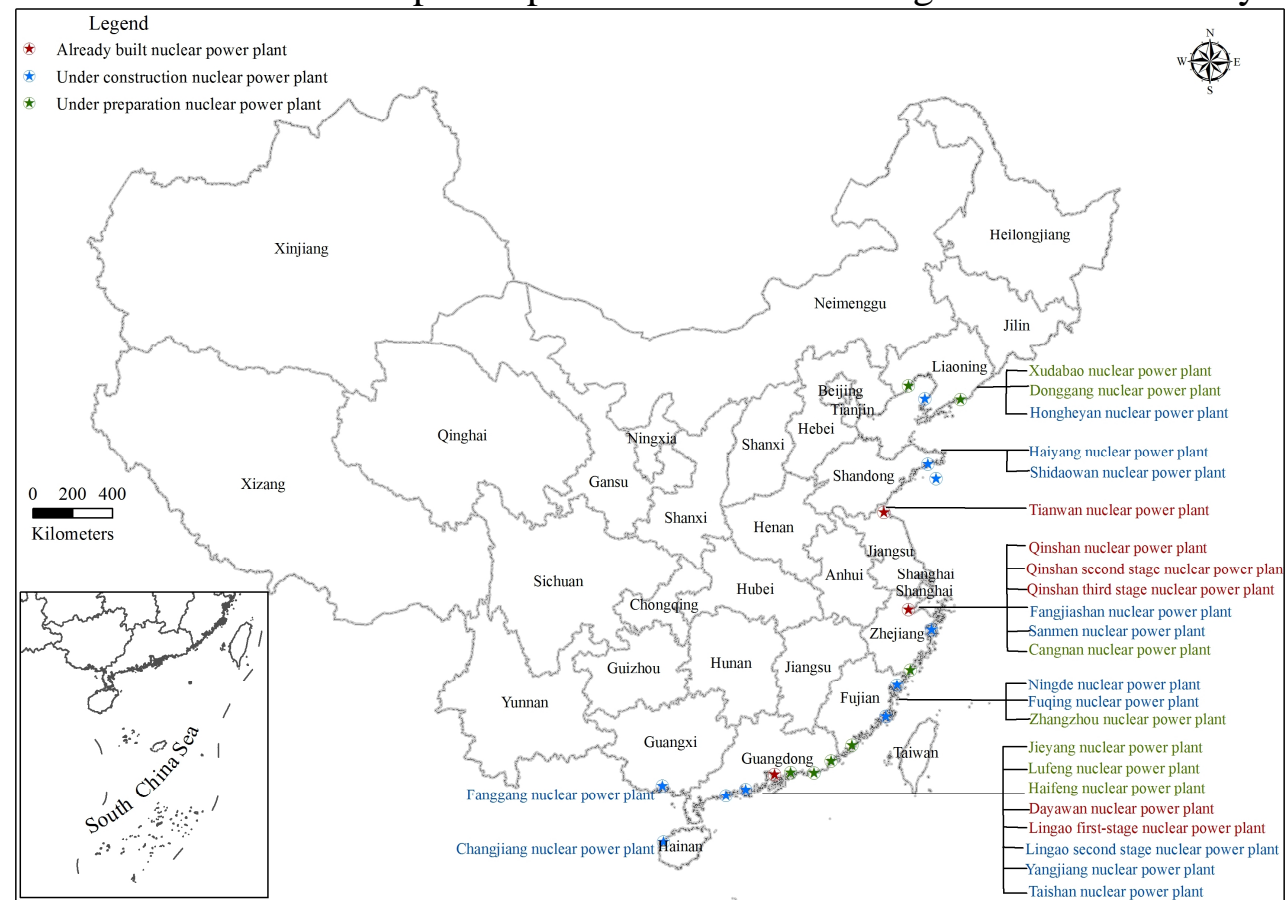

Fig. 1 Distribution of China's coastal nuclear power plants (already built, under construction, under preparation)

\section{Main Impact of Nuclear Power Plant Construction on Marine Environment}

At present, the nuclear power plants that have been built and are under construction are concentrated in coastal regions, and most of them are sited in the bays. Bay areas generally are economically developed population centers. Based on consideration of nuclear safety, the development of nuclear power has special requirements for the usage of land and sea and the degree of population density. Meanwhile, bay areas generally are ecologically sensitive areas, with poor hydrodynamic and water exchange conditions. The dense distribution of nuclear power plants in coastal regions, especially the bay areas, will inevitably result in greater pressure to the marine environment.

The shortage of land for construction of coastal nuclear power plants shall be covered through reclamation. Moreover, intake and drainage systems shall be built in suitable maritime space, and the problem of cooling water in open thermal discharge maritime space shall be solved. The construction processes of dredging, revetment and diversion in heavy goods wharf harbor basin and swirling maritime space will adversely affect the environmental quality and ecological environment of local maritime space. These impacts include the following aspects [4]:

\section{The impact on the marine environment during the construction.}

Construction of nuclear power plants involves land reclamation. The destruction caused to the ecological environment of coast zone by land reclamation is mainly embodied in: all aquatic life, including intertidal organisms, benthos, zooplankton, fish eggs and larvae and so on, which originally inhabit in this region and are incapable of escaping, are buried and die due to reclamation activities. The permanent occupation of marine space by reclamation causes permanent loss and irreversibility to the ecological functions of fishery in the maritime space, especially the permanent loss to the reproductive capacity of fishery resources, and affects the regulatory and complementary role of marine organisms spawning ground and nursery habitat space in maintaining the ecological balance of fishery in the maritime space. Meanwhile, in the reclamation process, the overflow of suspended solids increases the concentration of suspended solids in the seawater, affecting the growth of aquatic organisms. In the settlement process, coarse sediment directly buries or harms the organisms in adjacent areas, especially the juveniles. Seawater turbidity affects photosynthesis and impedes air-sea exchange, thus leading to death of the organisms due to a lack of oxygen in the water body [5]. 
The construction of some nuclear power plants also involves underwater blasting. The harmful effects of underwater blasting mainly come from three aspects: surge waves, seismic waves and individual scattering substances. Compared with land blasting, the shock waves generated from underwater blasting are featured by large impulse and slow decay in the water body, thereby greatly threatening the safety of aquatic organisms, coastal and aquatic architectural structures, ships and underwater operators [6].

\section{The impact on the marine environment during the operation.}

The entrainment effect of intake and drainage system only produces significant damage to fish eggs, larvae, larval shrimps, plankton and other swimming type biological larvae that can pass through the strainer of water intake system. Entrainment effect consists of three elements: the impact of instantaneous high temperature (thermal effect) within the system, mechanical damage (mechanical effects, including changes in pressure), and chemical factors (including the artificial use of liquid chlorine in some plants to prevent pipe blockage). The results of these three elements vary under different conditions. High temperature shock effect is relatively obvious in Summer. Chemical factors are usually affected by concentration, dissolved diffusion an other factors. Mechanical damage is the most frequent and the most important hazardous factors among the three of them.

There are a advantage and a disadvantage to the impacts of thermal discharge in nuclear power plants on marine organisms and ecosystems advantages and disadvantages $[7 \sim 8]$. The advantage is that, in the season with low water temperature, the marine life abundance and biodiversity indices of medium or weak warming areas are greater than those of natural water bodies. The disadvantage is that, strong warming area may reduce marine habitat, especially in the hot season from July to September, warming may decrease the marine life abundance and biodiversity indices.

To avoid the increase in piped water resistance and the biological damage to the pipe wall surface due to the attachment of marine fouling organisms to the pipe wall of the circulating cooling system, and thus affect the economy of operation and the service life of circulating system, it is necessary to provide a chlorine dosing system in the circulating water system. Chlorination treatment prevents the multiplication of marine organisms in the pipeline, but after passing through the circulating system, undegraded chlorine will be discharged into the sea with thermal drainage, which causes a certain amount of residual chlorine in recycling drainage discharged from the nuclear power plant. Residual chlorine has biological toxicity. Relevant data indicate that the dose of chronic poisoning is $0.0015 \mathrm{mg} / \mathrm{L}$ for freshwater organisms, or $0.02 \mathrm{mg} / \mathrm{L}$ for salt-water organisms. In the event that the above concentration is exceeded, death can be caused to the organisms.

Recent studies show that due to the different living environments, the environmental radiation dose rates for many organisms are significantly greater than the ones for humans. Also, the radiation sensitivities for some deep-sea organisms are greater than the ones for humans. The results of monitoring Guangdong Daya Bay Nuclear Power Station (GNPS) for eight consecutive years show that the marine organisms in the bays, such as seaweed, fish and shellfish, have obvious adsorption with key radionuclides ${ }^{110 \mathrm{~m}} \mathrm{Ag}$. Therefore, the radioactive radiation impact of liquid radioactive effluents from nuclear power plants on the marine organisms in the discharge maritime space has begun to receive concern and attention from environmental review experts.

In order to meet the operational requirements of the nuclear power plants, the water used for relevant systems need to be chemically treated, i.e., adding a certain amount of corrosion inhibitor or chemically active additives (such as boric acid, lithium hydroxide, sodium oxide, ferric chloride, sodium hypochlorite, ammonia hydrazine, ammonia, etc.) in the system, in order to ensure that the water quality requirements. Except that a part of these chemicals enter the solid waste treatment, the rest will be eventually discharged into the marine environment with all types of waste water and recycling drainage. These chemicals may produce adverse effects on the quality of seawater and marine life.

\section{Main Elements Associated with Siting of Nuclear Power Plants}

The construction of nuclear power plants may have many far-reaching impacts on the surrounding marine environments, so the siting of nuclear power plants shall fully consider the marine elements 
that may be affected, including marine dynamic environment, ocean topography, islands, nature reserve, marine biological resources and so on, in order to minimize losses caused to the marine environment by the construction and operation of nuclear power plants. Based on the features of the maritime space used for nuclear power plants, the particularity of the marine environment, and the needs of accelerated development of coastal nuclear power and marine environmental protection, it is recommended that the siting of nuclear power plants in the future should take into account the following relevant marine elements:

Coastal nuclear power plants should be sited in the open maritime space with stable beaching and good hydrodynamic conditions, instead of semi-enclosed bays, estuaries or inner bays.

Coastal nuclear power plants need a lot of water from maritime space as cooling water, for extensive use for thermal discharge from nuclear power plants. So, the sea areas that provide poor hydrodynamic conditions and are easy to deposit, such as the semi-enclosed bays with poor water exchange capacities, and the estuaries and bays with sediment deposition, are not conducive to the dilution and dispersion of intake, thermal drainage and sewerage as well as the dispersion of low-level radioactive waste liquid into the water. According to the comparison of water intake indicators for nuclear power plants, which was presented in relevant studies (Table 1), beaching is stable, with balanced scouring and silting. In case the average sediment concentration is less than $0.5 \mathrm{~kg} / \mathrm{m}^{3}$, and the cooling water supply is greater than $20 \mathrm{~m}^{3} / \mathrm{s}$, the water intake condition is excellent, but the beaching is instable, with a wide range of beaches and continued siltation. In the event that the sediment concentration is greater than $2 \mathrm{~kg} / \mathrm{m}^{3}$, the water intake condition is poor.

Table1 Comparison of water intake condition indicators [9]

\begin{tabular}{|c|c|c|c|c|c|}
\hline $\begin{array}{c}\text { Feature } \\
\text { level }\end{array}$ & Beaching stability & $\begin{array}{l}\text { Water depth condition } \\
\text { distance between } 10 \mathrm{~m} \\
\text { depth contour and } \\
\text { shoreline } \mathrm{L} / \mathrm{km}\end{array}$ & $\begin{array}{l}\text { Water } \\
\text { route } \\
\text { length } \\
\mathrm{L} / \mathrm{km}\end{array}$ & $\begin{array}{c}\text { Average } \\
\text { Sediment } \\
\text { Concentrat } \\
\text { ion } \\
\mathrm{G} /(\mathrm{kg} / \mathrm{m} 3)\end{array}$ & $\begin{array}{l}\text { Amount of } \\
\text { cooling } \\
\text { water } \\
\text { supply } \\
\mathrm{Q} /(\mathrm{m} 3 / \mathrm{s})\end{array}$ \\
\hline Excellent & $\begin{array}{c}\text { Beaching is stable, with } \\
\text { balanced scouring and } \\
\text { silting }\end{array}$ & $<5$ & $<3$ & $<0.5$ & $>20$ \\
\hline Good & $\begin{array}{c}\text { Beaching is basically } \\
\text { stable, with slightly } \\
\text { changing scouring and } \\
\text { silting }\end{array}$ & $5<\mathrm{L}<10$ & $3<\mathrm{L}<15$ & $0.5<\mathrm{G}<2$ & $10<Q<20$ \\
\hline Poor & $\begin{array}{c}\text { Beaching is instable, } \\
\text { with a wide range of } \\
\text { beaches and continued } \\
\text { siltation }\end{array}$ & $>10$ & $>15$ & $>2$ & $<10$ \\
\hline
\end{tabular}

The water dispersion condition indicator (Table 2), with the bay area of more than $100 \mathrm{~km} 3$, the large open maritime space, and the average tidal range of greater than $3.5 \mathrm{~m}$, is excellent. And the water dispersion condition indicator with weak tidal cove, the average tidal range of less than $0.5 \mathrm{~m}$ and the area of less than $50 \mathrm{~km}^{2}$ is poor. Obviously, the semi-enclosed bays with poor hydrodynamic conditions and greater sediment concentrations are easy to form deposited estuaries and instable coastal beaches, and the inner bays with a wide range of beaches are not suitable for the siting of nuclear power plants. 
Table2 Comparison of water dispersion condition indicators

\begin{tabular}{cccc}
\hline Feature Level & Excellent & Good & Poor \\
Average tidal range $\mathrm{h}(\mathrm{m})$ & $>3.5$ & $0.5<\mathrm{h}<3.5$ & $<0.5$ \\
\hline \multirow{2}{*}{ Tidal conditions } & Very strong tidal surges & Medium tidal surges & Very weak tidal \\
Bay area $\mathrm{A}^{\prime}\left(\mathrm{km}^{2}\right)$ & and strong tidal surges & and weak tidal surges & surges \\
Water body scale & $>100$ & $50<\mathrm{A}^{\prime}<100$ & $<50$ \\
& Large open maritime & Medium maritime & Small maritime \\
& space & space & space \\
\hline
\end{tabular}

In addition, as important habitats for the survival and breeding of marine organisms, the coastal estuaries and bay areas, in which estuarine wetlands, mangroves, coral reefs, sea grass beds and other important ecosystems are distributed, biodiversity and important fishery resources, and which many unique rare and endangered species inhabit, play a very important role in the global ecological balance. However, coastal estuaries and bay areas are most affected by disturbance of human activities, so the ecosystems are extremely sensitive and fragile. In recent years, the rapid social and economic development of China's coastal areas has dramatically increased the demand for land. Also, a large number of reclamations have produced seriously negative impact on coastal ecosystems and ecological environment, thereby leading to deterioration in ecological environment, increasingly reduction in tidal wetlands, coastal erosion and siltation, extinction of rare and endangered species, biodiversity loss, and even severe degradation of ecosystem. According to the current trend of accelerating coastal nuclear power development, in order to protect the important ecological resources of estuaries and bays, it is necessary to restrict the siting of nuclear power projects involving large-scale maritime space use in estuaries and bays.

Reclamation and maritime space use works shall not produce a significant impact on the siltation environment of the maritime space for siting of coastal nuclear power plants, at the annual siltation intensity of less than $20 \mathrm{~cm} / \mathrm{a}$.

The construction of coastal nuclear power projects usually involve reclamation and marine construction, so the impact on the maritime space is mainly the change in hydrological conditions, resulting in reduced tidal volume, reduced environmental capacity of the maritime space, decreased seawater self-purification capacity, and decreased water quality, causing siltation, accelerating the accumulation of pollutants in the seabed, change seabed habitats and thus affecting the ecological environment of the maritime space. According to the evaluation on suitability of typical bay reclamation, it is deemed that reclamation works is suitable for the erosion indicator of $10 \sim 20 \mathrm{~cm} / \mathrm{a}$ or below. It is obvious that the siltation intensity of less than $20 \mathrm{~cm} / \mathrm{a}$ for the maritime space of coastal nuclear power plants will cause serious sediment deposition and be not conducive to water intake, thereby increasing the dredging costs and affecting the ecological environment of maritime space.

The siting of coastal nuclear power plants shall steer clear of ecologically sensitive areas, stateand province-level marine nature reserves, mangroves, seagrass beds, coral reefs distribution areas, important fishery resources spawning and nursery fields, rare and endangered species of national protected animals, and valuable cultural landscapes and historical sites.

Previous studies show that the thermal discharge of Daya Bay Nuclear Power Plant has a serious impact on the coral reefs, causing bleaching and degradation to the coral reefs of Daya Bay. The maritime space for Hainan Changjiang Nuclear Power Project is a coral reefs growing area. According to the assessment, the landfill and excavation of coral reefs for construction of nuclear power projects has caused loss to the coral reefs with the area of about $21.31 \mathrm{hm} 2$. Coral reefs are unique valuable biological resources in China's southeast coast. Due to the impact of global warming and human disturbance, worldwide degradation in coral reef ecosystem has occurred. In recent years, China' s coral reef ecosystems have degraded seriously, and even some maritime spaces have been on the verge of extinction. China' $s$ coastal wetland ecosystems are facing environmental degradation. Biodiversity loss, endangerment of rare species, severe recession of fishery resources and other ecological problems are intensifying. Thus, the thermal discharge for the siting of coastal 
nuclear power plants shall be $10 \mathrm{~km}$ above from the core area of marine sanctuary, and the seawater temperature rise range of $2{ }^{\circ} \mathrm{C}$ shall not be involved in the core area of marine sanctuary.

The siting of coastal nuclear power plants shall adhere to economical and intensive use of maritime space, in order to minimize the occupation of natural coastline, islands and other scarce resources.

The length of coastline is an essential element of coastal space resources as well as an important support for coastal ecosystems. Since most of reclamation works for China's nuclear power plants are located inside the bays, a direct consequence is the substantial reduction in the length of coastline after straightening and the destruction in coastal dynamic equilibrium. This results in reduction and even disappearance of natural coastline.

As an important part of coastal ecosystems, islands play an important role in maintaining a marine ecosystem health, promoting the development of marine economy, protecting national interests and safety, etc.. The reclamation works for some nuclear power plant projects have made the island into a land, losing natural island property. Due to the reclamation for Ningde Nuclear Power Plant, the group of islands have gradually developed into a peninsula, completely destroying the independence of the island ecosystems. Therefore, the siting of coastal nuclear power plants shall adhere to economical and intensive use of maritime space, in order to minimize the occupation of natural coastline, islands and other scarce resources.

\section{References}

[1] M. Mazen and Abu-Khader. Recent advances in nuclear power: A review. Progress in Nuclear Energy, Vol. 51 (2009), p. 225 235

[2] S.K. Jain. Inevitability of Nuclear Power in the Asian Region. Energy Procedia, Vol. 7 (2011), p. $5 \sim 20$

[3] Y. Qiang, A. J. Wang, and G. S. Wang. Nuclear power development in China and uranium demand forecast: Based on analysis of global current situation. Progress in Nuclear Energy, Vol. 53 (2011), p. 742 747

[4] Third Institute of Oceanography, State Oceanic Administration. Research report on use of sea areas for coastal nuclear power plants and its marine environmental impact. 2012

[5] Third Institute of Oceanography, State Oceanic Administration. Feasibility report on use of sea areas for Hainan Changjiang Nuclear Power Plant. 2009

[6] Nanjing Normal University. Feasibility report on use of sea areas for units \#5 and \#6 of Tianwan Nuclear Power Plant Expansion Project. 2009

[7] R. G. Li, J. Y. Jiang, and Q. Wu. Intertidal zone biomes near Daya Bay Nuclear Power Plant. Oceanologia Et Limnologia Sinica, Vol. 26 (1995), p. 91 101

[8] L. L. Wu, B. Yi, and D. Lin. Ecological Environmental Problems and Management Countermeasures for Daya Bay Ecological Monitoring Area. Ocean Development and Management, Vol. 126 (2009), p.14 20

[9] X. Xu, F. Zhao, and C. Tan. Consideration on environment-related hydrological conditions for siting of nuclear power plants. Chinese Nuclear Power, Vol. 3(2010), p. 80 85 